\title{
Erratum to: Special issue on best papers of VLDB 2015
}

\author{
Chen $\mathrm{Li}^{1}$. Volker Markl ${ }^{2}$
}

Published online: 9 February 2017

(C) Springer-Verlag Berlin Heidelberg 2017

\section{Erratum to: The VLDB Journal \\ DOI 10.1007/s00778-016-0450-5}

In the original publication, the second author's name was incorrectly published as Markl Volker. The correct name should read as Volker Markl.

The original article has been updated.

The online version of the original article can be found under doi:10.1007/s00778-016-0450-5.

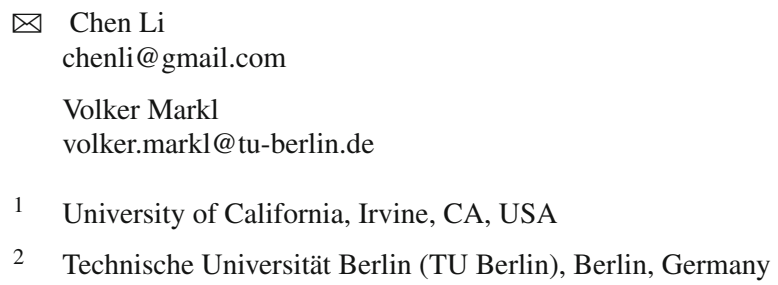

2 Technische Universität Berlin (TU Berlin), Berlin, Germany 